\title{
Valor dos biomarcadores tissulares e do pet-ct no prognóstico do câncer de cabeça e pescoço: revisão do paradigma diagnóstico e terapêutico
}

\section{Value of tissue biomarkers and pet-ct in the prognosis of head and neck cancer: review of diagnostic and therapeutic paradigm}

Abrão Rapoport, ECbC-SP1; Helma Maria Chedid ${ }^{2}$; Ricardo Pires de Souza 3

O câncer mais frequente na cabeça e pescoço é o carcinoma epidermóide, sendo que o diagnóstico ocorre em fase avançada (estádios clínicos III e IV) em 70\% a $80 \%$ dos casos. A detecção precoce e o estadiamento corretos são importantes no planejamento terapêutico e no prognóstico do paciente. Após o tratamento inicial, o momento do diagnóstico da recidiva loco-regional é essencial no planejamento do resgate cirúrgico, visto que $70 \%$ das recidivas ocorrem nos primeiros 24 meses, como lesão residual ou apresentação subclínica. Ademais, a presença da metástase hematogênica comumente é irresponsiva à terapêutica habitual, apesar de sua baixa frequência (inferior a $10 \%)$.

Exame direto completo e minucioso é acessível ao especialista, e, quando associado ao exame histopatológico pode fornecer o diagnóstico e o estadiamento na apresentação inicial do paciente. Aos exames complementares convencionais urge a necessidade de criação de protocolos de estadiamento na decisão terapêutica inicial e, especialmente, no re-estadiamento para validação científica de uma ferramenta científica, ainda, pouca utilizada em vários centros médicos no país.

Mudança do paradigma patológico - O carcinoma epidermóide é histologicamente bem definido. Dentre os critérios histológicos como fatores prognósticos de maior impacto temos a ruptura capsular macroscópica e rela- ção entre a fronte de invasão e o estroma. A partir da década de 70, surgiram novas técnicas nos laboratórios de patologia e imuno-histoquímica, com o objetivo de auxiliar na identificação de linhagens histogênicas, incorporandose mais tarde, às pesquisas de fatores prognósticos. Os biomarcadores teciduais ganharam cada vez maior importância, em especial, no que se refere ao diagnóstico precoce, monitoramento e planejamento terapêutico. Dentre os inúmeros marcadores moleculares, inexiste um painel universal, sendo os mais estudados o p16, p53, CCNDI, EGF, VEGF e HPV.

Mudança no paradigma imagenológico - O estudo dos métodos de imagem pode auxiliar no estadiamento clínico, avaliando a extensão profunda da lesão primária e eventuais disseminações linfonodais e/ou à distância, interferindo em muitos casos, nas decisões terapêuticas. Os principais métodos de imagem do estadiamento do carcinoma epidermóide da cabeça e pescoço são a tomografia (CT) e a ressonância nuclear magnética (RNM).

A tomografia por emissão de pósitrons associada à técnica do 18F-FDG-PET tem utilização recente para o câncer de cabeça e pescoço e indicação crescente. Todavia, a discussão de sua utilização no diagnóstico e tratamento inicial tem indicações limitadas, nas quais o exame direto e eventuais exames de imagens convencionais são suficientes para uma terapêutica adequada.

1. Departamento de Cirurgia de Cabeça e Pescoço e Otorrinolaringologia do Hospital Heliópolis, Hosphel, São Paulo, BR; 2. Cirurgiã de Cabeça e Pescoço e Doutoranda da Faculdade de Medicina da Universidade de São Paulo. 3. Radiologista do Hospital Heliópolis, São Paulo. 